\title{
Super Active Catalyst for Olefin Polymerization
}

\author{
Norio KASHIWA \\ Research Center, Mitsui Petrochemical Industries, Ltd., \\ Waki-cho, Kuga-gun, Yamaguchi-ken, 740, Japan.
}

(Received April 15, 1980)

\begin{abstract}
Study to get a high activity for olefin polymerization by a supporting Ziegler-type catalyst on $\mathrm{MgCl}_{2}$ was carried out. Only heating anhydrous $\mathrm{MgCl}_{2}$ with $\mathrm{TiCl}_{4}$, very little amount of $\mathrm{TiCl}_{4}$ was fixed because of high crystallinity and small surface of anhydrous $\mathrm{MgCl}_{2}$. A pretreatment by some organic electron donner such as butanol or methyl acetate before the reaction with $\mathrm{TiCl}_{4}$, resulted a considerable fixation of $\mathrm{TiCl}_{4}$ onto $\mathrm{MgCl}_{2}$ and gave high activity for ethylene polymerization by $70-90$ times of conventional $\mathrm{TiCl}_{3}$ catalyst. The study of the $\mathrm{TiCl}_{4}-\mathrm{MgCl}_{2}$ comilling, the other supporting technique, was also investigated. There are efficient $\mathrm{Ti}$ and inefficient ones to participate in the formation of active species among the fixed Ti. The titanium fixed in the initial stage of milling at the active site of broken $\mathrm{MgCl}_{2}$ particle surface was rather efficient. Furthermore, The high stereospecificity was performed for propylene polymerization, by arranging some organic electron donner around $\mathrm{Ti}$ for the above mentioned $\mathrm{TiCl}_{4}-\mathrm{MgCl}_{2}$ catalyst.

KEY WORDS Ziegler Catalyst / Supported Catalyst / $\mathrm{TiCl}_{4} / \mathrm{MgCl}_{2}$ /

Olefin Polymerization / Ethylene / Propylene / Active Species /
\end{abstract}

Since the finding of Ziegler catalyst in early 1950 s, polyolefin manufacturing industry using saidcatalyst has accomplished really epochmaking progress in both catalyst and process based upon piles of improvements. Among all, as a result of developments of a series of highly-active supported catalyst accompanying a great deal of simplification on the production process and the energy-saving.

We have found various super-active catalysts for ethylene or propylene polymerization, and we are successful of its industrialization.

In this paper, we would make our report on the super-active catalyst using $\mathrm{MgCl}_{2}$ as the carrier.

\section{HIGH-ACTIVITY CATALYST PREPARATION}

\section{High-Activity Catalyst}

$\mathrm{TiCl}_{3}$ catalyst which is the conventional one is regarded to have a low ratio ${ }^{1}$ of efficient titanium to participate in the formation of active species, so that to improve the ratio, many experiments have attempted to attain as high Ti dispersion as possible by supporting titanium compounds on carriers.

In contrast to the above technique, we expected the supporting effect might be realized to the most extent when achieved "the continuous structure" between titanium compound and the carrier. In other words, it means to make "pseudo- $\mathrm{TiCl}_{3}$ " composed of carrier and titanium compound, by using the carrier having a very similar crystalline structure as with $\gamma-\mathrm{TiCl}_{3}$, and packing $\mathrm{TiCl}_{4}$ at the edge portion of the carrier which might be most reactive site.

And then, $\mathrm{MgCl}_{2}$ should be most suitable compound for the carrier because of its crystalline similarity to $\gamma-\mathrm{TiCl}_{3}$ and very close values of ionic radius, $\mathrm{Ti}^{4+}$ and $\mathrm{Mg}^{2+}$, respectively $0.68 \AA$ and $0.65 \AA$.

The model of this supporting concept is as follows.

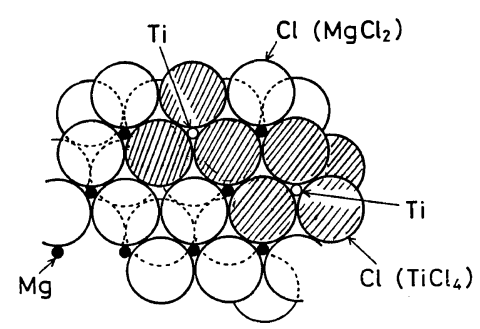

Figure 1. Model for $\mathrm{TiCl}_{4}$ trapping onto $\mathrm{MgCl}_{2}$ matrix edge portion. 
High-Activity, High-Stereospecificity Catalyst

Cossee $^{6}$ in reference to the particular exhibition of high stereospecificity when propylene was polymerized using $\mathrm{TiCl}_{3}$ as the catalyst, presented the explanations that the stereoscpecific positions of $\mathrm{Cl}$ atoms on $\mathrm{TiCl}_{3}$ are controlling the coordination direction of propylene monomer, which hitherto has been generally accepted.

Accordingly, we thought a high stereospecificity would be exhibited if the ligand around Ti could take a similar stereospecific position as with $\mathrm{Cl}$ atoms on $\mathrm{TiCl}_{3}$ even with such a structure where $\mathrm{TiCl}_{4}$ was supported onto $\mathrm{MgCl}_{2}$; that is, we thought to arrange an electron donner around $\mathrm{Ti}$ for the above-mentioned $\mathrm{TiCl}_{4}-\mathrm{MgCl}_{2}$ catalyst as a controlling substance of the stereospecific position.

\section{RESULTS AND DISCUSSION}

\section{High-Activity Catalyst for Ethylene Polymerization}

The thermoreaction between anhydrous $\mathrm{MgCl}_{2}$ powder $(20-140 \mu \mathrm{m})$ and $\mathrm{TiCl}_{4}$ did not result in almost any fixation of Ti. This is thought to be due to the small surface area of anhydrous $\mathrm{MgCl}_{2}$ and also its high crystallinity.
Therefore, we firstly had $\mathrm{MgCl}_{2}$ react with electron donner, broke down tough $\mathrm{MgCl}_{2}$ crystalline structure, and then tried to let it react with $\mathrm{TiCl}_{4}$ nearly at the boiling point.

Step 1. $\mathrm{MgCl}_{2}$ with 2-mol times butanol, or the same mol methyl acetate were reacted in kerosene at $80^{\circ} \mathrm{C}$ for $2 \mathrm{~h}$, and the resulted white powder was separated and washed.

Step 2. The above white powder was reacted with an excess $\mathrm{TiCl}_{4}$ at $135^{\circ} \mathrm{C}$ for $2 \mathrm{~h}$. Obtained yellowish powder was washed by hexane until no Ti was detected in the washed liquid.

Changes in composition and structure at each step are given in using 1-butanol in Table I.

Considerable amount of $\mathrm{TiCl}_{4}$ was fixed on $\mathrm{MgCl}_{2}$ and the catalyst can be expressed by the composition of $\mathrm{MgCl}_{2} \cdot 0.22 \mathrm{TiCl}_{4}$. The specific surface area increased by 390 times of material $\mathrm{MgCl}_{2}$. The activity of this catalyst in ethylene polymerization is given in Table II. Compared with the commercial $\mathrm{TiCl}_{3}$ catalyst, the activity per unit $\mathrm{Ti}$ truly increased by 70-90 times, thus the effective utilization of Ti was accomplished. It is considered that $\mathrm{MgCl}_{2}$ has, besides its dispersion capability of Ti to a great extent, a role of raising the activity of

Table I. Changes in composition and structure at each step of preparation of the catalyst in using $\mathrm{BuOH}$

\begin{tabular}{|c|c|c|c|c|c|}
\hline & \multicolumn{3}{|c|}{ Composition/wt $\%$} & \multirow{2}{*}{$\frac{\text { Specific surface area }}{\mathrm{m}^{2} \mathrm{~g}^{-1}}$} & \\
\hline & $\mathrm{Mg}$ & $\mathrm{Cl}$ & $\mathrm{Ti}$ & & \\
\hline Material & & $\mathrm{MgCl}_{2}$ & & 0.75 & High-crystalline $\mathrm{MgCl}_{2}$ \\
\hline 1st step ${ }^{a}$ & & 32 & - & 1.49 & Crystal different from $\mathrm{MgCl}_{2}$ \\
\hline 2nd step ${ }^{b}$ & & 71 & 8.2 & 292 & Low-crystalline substance \\
\hline
\end{tabular}

${ }^{\text {a }} \mathrm{MgCl}_{2}+2-\mathrm{BuOH}$, dried after washing by hexane.

b $\left(\mathrm{MgCl}_{2}+2-\mathrm{BuOH}\right)+12 \mathrm{TiCl}_{4}$, dried after washing by hexane.

Table II. Ethylene polymerization activity of our catalysts and commercial $\mathrm{TiCl}_{3}$ catalyst ${ }^{\mathrm{a}}$

\begin{tabular}{lccc}
\hline \multirow{1}{*}{ Catalyst } & & $\mathrm{Al} / \mathrm{Ti}$ & Activity \\
& Co-catalyst & & $\mathrm{g} \cdot \mathrm{PE} / \mathrm{mmol}-\mathrm{Ti} \cdot \mathrm{h}^{-1}$ \\
\hline $\mathrm{C}-1$ (1-butanol used) & & 50 & 1,800 \\
$\mathrm{C}-2$ (methylacetate used) & $\mathrm{Et}_{3} \mathrm{Al}$ & 50 & 1,400 \\
$\mathrm{TiCl}_{3} \cdot(1 / 3) \mathrm{AlCl}_{3}$ & $\mathrm{Et}_{3} \mathrm{Al}$ & 50 & 20 \\
\hline
\end{tabular}

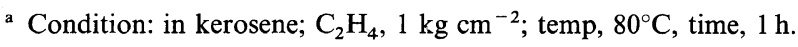


every $\mathrm{Ti}$ atom through some sort of electrical effect.

\section{$\mathrm{TiCl}_{4}$ Fixation onto $\mathrm{MgCl}_{2}$ by Ball Milling}

The catalyst ${ }^{7}$ obtained by mechanically co-milling $\mathrm{TiCl}_{4}$ and $\mathrm{MgCl}_{2}$ is one of $\mathrm{TiCl}_{4}$ supported on $\mathrm{MgCl}_{2}$ catalyst systems exhibiting high activity to olefin polymerization. And this co-milling method is very simple one, so that taking this as the topic, detail studies were made to clarify the behavior of fixation of $\mathrm{TiCl}_{4}$ onto $\mathrm{MgCl}_{2}$.

$0.5-150 \mathrm{~h}$ co-milling was made with $\mathrm{TiCl}_{4} / \mathrm{MgCl}_{2}$ molar ratio 0.12 , SUS-made ball milling system (the apparent void $30 \%$ ) and room temp, $120 \mathrm{rpm}$; after which unfixed $\mathrm{TiCl}_{4}$ was removed by washing. Also for comparison, a milling of $\mathrm{MgCl}_{2}$ alone was made.

The specific surface area and the half-width of (003) peak of $\mathrm{MgCl}_{2}$ increased as milling and after $60-80 \mathrm{~h}$, they maintained maximum values, respectively 800 times and 100 times of those of

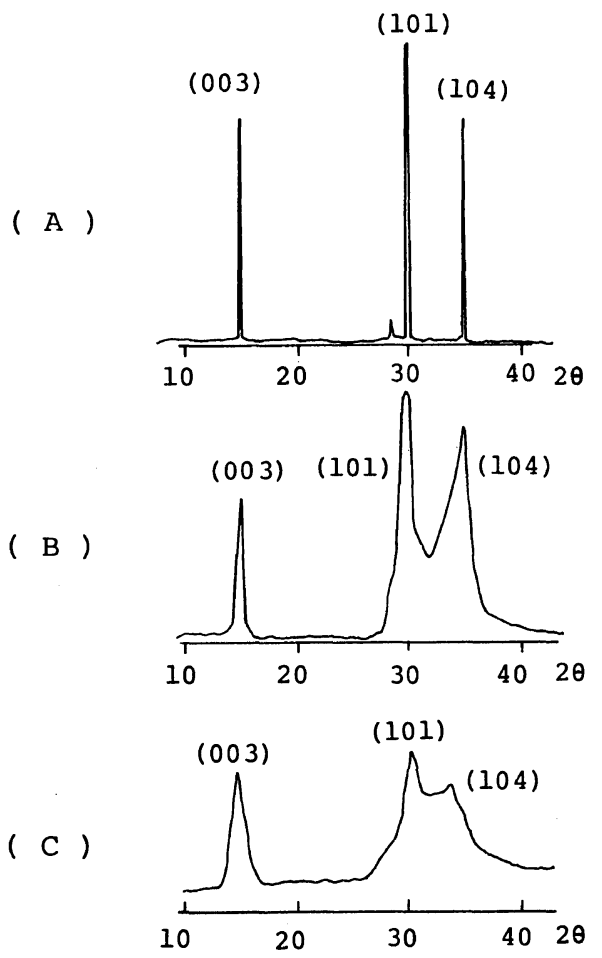

Figure 2. X-ray diffraction pattern of milled $\mathrm{MgCl}_{2}$ : (A) Material $\mathrm{MgCl}_{2}$; (B) $\mathrm{MgCl}_{2}$ alone $25 \mathrm{~h}$ milling; (C) $\mathrm{MgCl}_{2}+0.12 \mathrm{TiCl}_{4}, 25 \mathrm{~h}$ milling. material $\mathrm{MgCl}_{2}$ (Figures 2, 3, and 4). Then $\mathrm{MgCl}_{2}$ would be suggested to be very suitable compound for our purpose, because relatively easy breakdown of its crystal would be expected to result in easy trapping of $\mathrm{TiCl}_{4}$ at its coordinatingly unsaturated portion.

On the other hand, co-milling $\mathrm{MgCl}_{2}$ with $\mathrm{TiCl}_{4}$, $\mathrm{TiCl}_{4}$ was fixed onto $\mathrm{MgCl}_{2}$ and its amount increased with co-milling time and about $60 \mathrm{~h}$ it reached maximum value, $40 \mathrm{mg} \mathrm{g}^{-1}$ catalyst (about $80 \%$ of added titanium was fixed). The specific surface area increased very fast compared with $\mathrm{MgCl}_{2}$ alone system and via subsequent constant value period, decreasing period were observed (Figure 3).

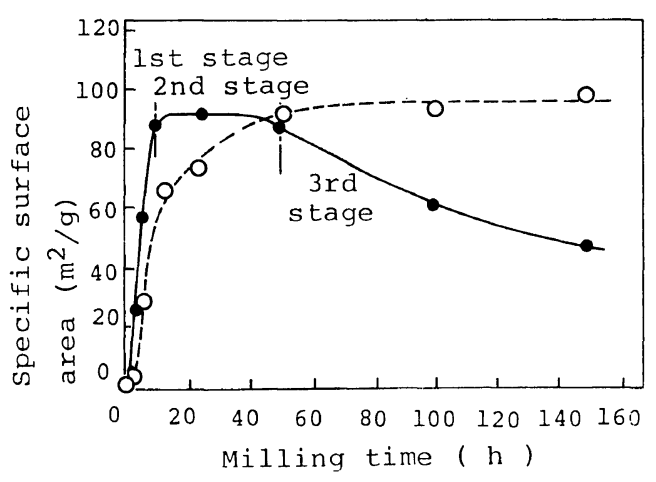

Figure 3. Change of surface area of $\mathrm{MgCl}_{2}$ for the milling time: --O--, $\mathrm{MgCl}_{2}$ alone milling; -- -$\mathrm{MgCl}_{2}+0.12 \mathrm{TiCl}_{4}$, milling.

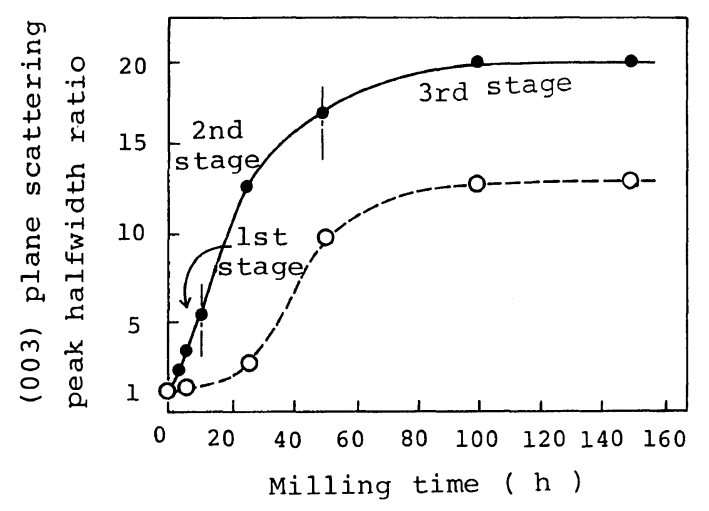

Figure 4. Change of half-width of (003) peak of $\mathrm{MgCl}_{2}$ for the milling time: --O--, $\mathrm{MgCl}_{2}$ alone milling; ,$--- \mathrm{MgCl}_{2}+0.12 \mathrm{TiCl}_{4}$, milling. 
The elapse in change of specific surface area, (003) peak width and amount of fixed $\mathrm{TiCl}_{4}$ could classify into three stages as given in Figures 3, 4, and 5.

These three stages could be understood as follows that $\mathrm{TiCl}_{4}$ go on to be fixed onto fresh cleavage surface by the fineness of $\mathrm{MgCl}_{2}$ (1st stage); moreover, fixed Ti makes a function as though it is a sort of wedge accelerating a further high destruction of $\mathrm{MgCl}_{2}$ crystalline structure and the newly resultant $\mathrm{Ti}$ fixation and that, at the same time, the fixed $\mathrm{Ti}$ was found to participate in the reaggregation of particles (2nd stage). And, in the 3rd stage, no new $\mathrm{Ti}$ fixation occurs and only the particle reaggregation proceeds.

Figure 6 exhibits the relations between Ti fixation amount and the activity for ethylene poly-

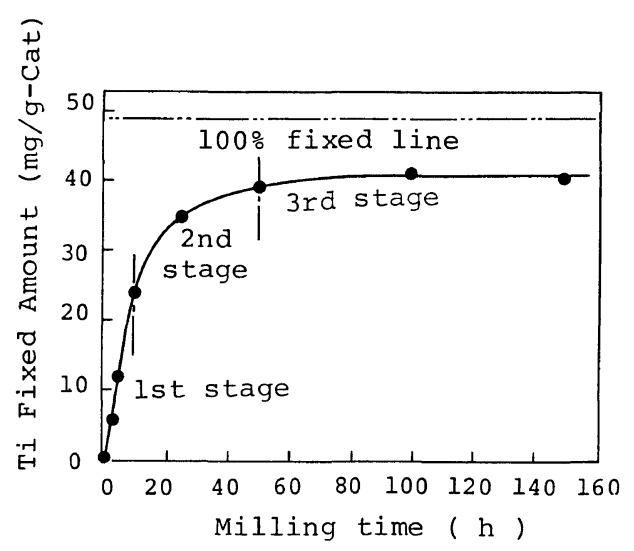

Figure 5. Change of $\mathrm{TiCl}_{4}$ fixed amount for the milling time $\left(\mathrm{TiCl}_{4} / \mathrm{MgCl}_{2}\right.$ molar ratio, 0.12). merization. Interestingly, the changes in polymerization activity corresponded with the three stages in the fixation elapse.

In the 1st stage, a higher activity exists where there was less Ti fixed amount; in other words, there were higher effective $\mathrm{Ti}$ ratio in the lower Ti fixation amount, which would have let us expect to show that Ti only at the edge part, which is easily fixable, participate in the formation of active species. In the 2nd stage, there occurs high breakdown of $\mathrm{MgCl}_{2}$ particles, and the activity makes a linear increase against the increase of $\mathrm{Ti}$ fixation amount. Furthermore, the reaggregation of catalyst particles down to 2 nd-3rd stage was found to be easily

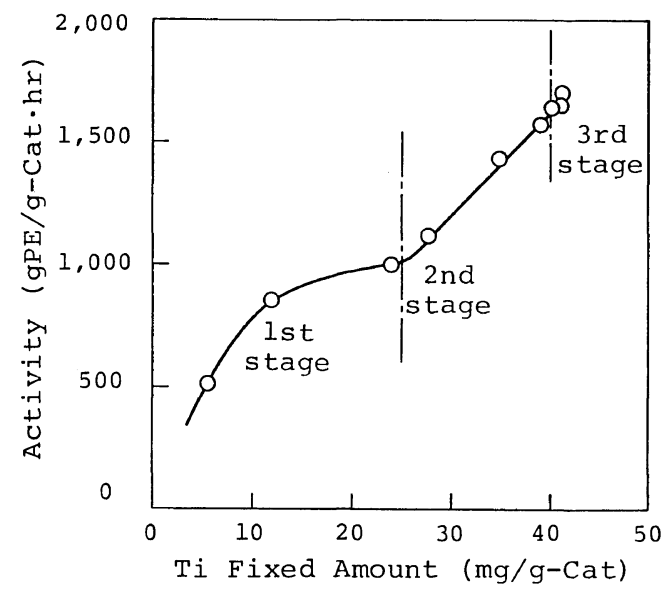

Figure 6. Relation between $\mathrm{Ti}$ fixed amount and ethylene polymerization activities. Condition: in kerosene; $\mathrm{C}_{2} \mathrm{H}_{4}, 1 \mathrm{~kg} \mathrm{~cm}^{-2}$; temp, $80^{\circ} \mathrm{C}$; time, $1 \mathrm{~h}$.

Table III. Comparison of ethylene polymerization activity between the co-milling catalyst and $\mathrm{TiCl}_{3}$ catalyst using various co-catalysts ${ }^{\mathrm{a}}$

\begin{tabular}{|c|c|c|c|c|c|}
\hline \multirow{2}{*}{ Catalyst } & \multirow{2}{*}{ Co-catalyst } & Ti concn & \multicolumn{2}{|c|}{ Al conen } & \multirow{2}{*}{$\frac{\text { Activity }}{\mathrm{g}-\mathrm{PE} / \mathrm{mmol}-\mathrm{Ti} \cdot \mathrm{h}^{-1}}$} \\
\hline & & $\mathrm{mmol}^{-1}$ & $\mathrm{mmol} \mathrm{1}^{-1}$ & ${ }^{1} \mathrm{Al} / \mathrm{Ti}$ & \\
\hline$C-1^{b}$ & $\mathrm{Et}_{3} \mathrm{Al}$ & 0.04 & 1.0 & 25 & 1,650 \\
\hline " & $\mathrm{Et}_{2} \mathrm{AlCl}$ & 0.2 & 5.0 & " & 330 \\
\hline " & $\mathrm{Et}_{1.5} \mathrm{AlCl}_{1.5}$ & 0.2 & 5.0 & " & 20 \\
\hline $\begin{array}{l}\mathrm{TiCl}_{3} \\
\text { (TAC-131) }\end{array}$ & $\mathrm{Et}_{3} \mathrm{Al}$ & 3.0 & 75 & $"$ & 20 \\
\hline " & $\mathrm{Et}_{2} \mathrm{AlCl}$ & 3.0 & 75 & " & 12 \\
\hline " & $\mathrm{Et}_{1.5} \mathrm{AlCl}_{1.5}$ & 6.0 & 150 & " & 1.5 \\
\hline
\end{tabular}

a In $500 \mathrm{ml}$ kerosene; temp, $80^{\circ} \mathrm{C}$; time, $1 \mathrm{~h}$.

b $\mathrm{TiCl}_{4}-\mathrm{MgCl}_{2}$ co-milling catalyst; $25 \mathrm{~h}$ milling; $\mathrm{Ti}, 36 \mathrm{mg} \mathrm{g} \mathrm{g}^{-1} ; 81 \mathrm{~m}^{2} \mathrm{~g}^{-1}$. 
Table IV. Comparison of propylene polymerizing performance between the co-milling catalyst and $\mathrm{TiCl}_{3}$ catalyst 'using various co-catalysts ${ }^{\mathrm{a}}$

\begin{tabular}{|c|c|c|c|c|}
\hline \multirow{2}{*}{ Catalyst } & \multirow{2}{*}{ Co-catalyst } & \multirow[t]{2}{*}{$\mathrm{Al} / \mathrm{Ti}$ ratio } & Activity & \multirow{2}{*}{$\frac{\text { Isotacticity index }}{\%}$} \\
\hline & & & $\mathrm{g}-\mathrm{PP} / \mathrm{mmol}-\mathrm{Ti} \cdot \mathrm{h}^{-1}$ & \\
\hline $\mathrm{TiCl}_{3}$ & $\mathrm{Et}_{3} \mathrm{Al}$ & 1 & 18.1 & 56.9 \\
\hline "I & $\mathrm{Et}_{2} \mathrm{AlCl}$ & 1 & 2.0 & 93.3 \\
\hline$C-1^{b}$ & $\mathrm{Et}_{3} \mathrm{Al}$ & 5 & 870 & 49.2 \\
\hline " & $\mathrm{Et}_{2} \mathrm{AlCl}$ & 5 & 45 & 33.0 \\
\hline
\end{tabular}

${ }^{\text {a }}$ In $500 \mathrm{ml}$ kerosene; temp, $70^{\circ} \mathrm{C}$, time, $1 \mathrm{~h}$.

b Same as in Table III.

broken down by the growth of polyethylene chains and does not cause the activity decrease.

The above results indicate that, of the fixed $\mathrm{Ti}$ compounds onto $\mathrm{MgCl}_{2}$, there are those that can become active species and those can not, and those fixed onto $\mathrm{MgCl}_{2}$ edge portion are effective.

Comparison of polymerization performance of the catalyst and $\mathrm{TiCl}_{3}$ catalysts using various kinds of co-catalyst was put in Table III for ethylene polymerization and in Table IV for propylene. In the ethylene polymerization the activity ratio of $\mathrm{TiCl}_{3}$ catalyst stands to be $13: 8: 1$ by changing organic aluminium to triethylaluminium, diethylaluminium chloride, and ethylaluminium sesquichloride; against these results, however, in the case of the $\mathrm{MgCl}_{2}$ supported catalyst of this study, the corresponding ratio becomes $83: 17: 1$ which is by far different.

Also with the propylene polymerization, the stereospecific dependency in the type of co-catalyst made contrary with the $\mathrm{TiCl}_{3}$ catalyst and with the supported catalyst.

Thus, this supported catalyst shows considerably different polymerization behaviors from $\mathrm{TiCl}_{3}$ catalyst, and it indicates that this super-high active $\mathrm{MgCl}_{2}$ supported $\mathrm{TiCl}_{4}$ catalyst is different from the one in which micro-fined $\mathrm{TiCl}_{3}$ is mere dispersed on $\mathrm{MgCl}_{2}$ carrier.

\section{High-Activity, High-Stereospecificity Catalyst}

In the preparation method of high-activity catalyst as described in 3.1, 1-butanol or methyl acetate which were coordinated to $\mathrm{MgCl}_{2}$, were almost all eliminated by the subsequent reaction with $\mathrm{TiCl}_{4}$ from the solid portion. Therefore, to find the electron donners that would not eliminate by the
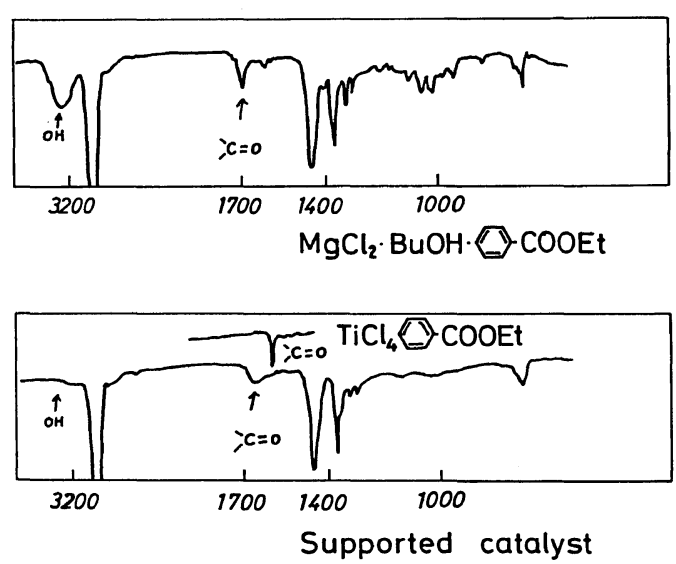

Figure 7. IR spectra of $\mathrm{CO}$ group in ethyl benzoate.

reaction with $\mathrm{TiCl}_{4}$, many compounds were examined and aromatic esters were found to be suitable.

Similar preparation method was used as given in 3.1 except both butanol and ethyl benzoate which is one of aromatic esters were coexisted in the Step 1.

Likewisely $\mathrm{TiCl}_{4}$ was fixed and small amount of ethyl benzoate remained in the catalyst.

IR absorption of $\mathrm{CO}$ group in ethylbenzoate was observed in the middle position of those absorptions between $\mathrm{MgCl}_{2} \cdot$ (O) COOEt and $\mathrm{TiCl}_{4} \cdot$ (O) COOEt (Figure 7), and it indicates that the ethyl benzoate is being fixed in such a mutual interaction for both $\mathrm{MgCl}_{2}$ and $\mathrm{TiCl}_{4}$.

Results of propylene polymerization by using the subject catalyst are exhibited in Table V, from which it was found that yield of stereospecific polymer reached $93.5 \%$. Simultaneously with the higher activation, and accomplished higher stereospecificity by the ethyl benzoate coordination. 


\section{N. KASHIWA}

Table V. Comparison of propylene polymerizing performance resulting from the existence or absence of ethyl benzoate on catalyst ${ }^{\mathrm{a}}$

\begin{tabular}{|c|c|c|c|c|c|}
\hline \multirow{2}{*}{ Catalyst } & \multirow{2}{*}{ Co-catalyst } & \multirow{2}{*}{$\mathrm{Al} / \mathrm{Ti}$ ratio } & \multirow{2}{*}{$\frac{\text { Temperature }}{{ }^{\circ} \mathrm{C}}$} & \multirow{2}{*}{$\frac{\text { Activity }}{\mathrm{g}-\mathrm{PP} / \mathrm{mmol}-\mathrm{Ti} \cdot \mathrm{h}^{-1}}$} & \multirow{2}{*}{$\frac{\text { Isotacticity index }}{\%}$} \\
\hline & & & & & \\
\hline $\mathrm{C}-\mathrm{II}^{\mathrm{b}}$ & $\mathrm{Et}_{3} \mathrm{Al}$ & 3.2 & 60 & 710 & 93.5 \\
\hline $\mathrm{C}-\mathrm{II}^{\mathrm{b}}$ & $\mathrm{Et}_{3} \mathrm{Al}$ & 5 & 70 & 1,200 & 70.1 \\
\hline $\mathrm{C}-\mathrm{I}^{\mathrm{c}}$ & $\mathrm{Et}_{3} \mathrm{Al}$ & 5 & 70 & 870 & 49.2 \\
\hline $\mathrm{TiCl}_{3}$ & $\mathrm{Et}_{2} \mathrm{AlCl}$ & 1 & 70 & 2 & 93.3 \\
\hline
\end{tabular}

a In $500 \mathrm{ml}$ kerosene; $\mathrm{C}_{3} \mathrm{H}_{6}, 1 \mathrm{~kg} \mathrm{~cm}^{-2}$, time, $1 \mathrm{~h}$.

b The present catalyst.

c The same as C-1 in Table III.

\section{REFERENCES}

1. For example, H. W. Coover, Jr., J. E. Guillet, R. L. Combs, and F. B. Joyver, J. Polym. Sci., A-1, 4, 2583 (1966).

2. British Petrochemicals Co., Br. Patent 841,822 (1955).
3. Sun Oil, Co., U.S. Patent 3,153,634 (1956).

4. Cabot Co., Br. Patent 761-767, 969 (1960-1963).

5. Solvey \& Cie Co., U.S. Patent 3400110 (1963).

6. Cossee, Tetrahed. Lett., 17, 12 (1960).

7. Montecatini Edison Co., Br. Patent 1286867 (1968); Mitsui Petrochemicals Industries, Ltd., Italy Patent 912345 (1968). 